\title{
Antibiotic sensitivity pattern of bacterial isolates from sputum samples of admitted patients with acute lower respiratory tract infections in a tertiary care teaching hospital of Tripura: a hospital record-based study
}

\author{
Shubhaleena Debnath, Debasree Bhaumik*, Maitrayee Chakraborty, Ranjib Ghosh, \\ Lakshman Das, Prithul Bhattacharjee
}

Department of Pharmacology, Tripura Medical College and Dr. B. R. Ambedkar Memorial Teaching Hospital, Agartala, Tripura, India

Received: 30 December 2019

Revised: 20 January 2020

Accepted: 21 January 2020

\section{*Correspondence:}

Dr. Debasree Bhaumik,

Email: dr.deby4u@gmail.com

Copyright: (C) the author(s), publisher and licensee Medip Academy. This is an open-access article distributed under the terms of the Creative Commons Attribution Non-Commercial License, which permits unrestricted non-commercial use, distribution, and reproduction in any medium, provided the original work is properly cited.

\begin{abstract}
Background: Antibiotics are frequently used for various infectious diseases e.g., acute lower respiratory tract infection (ALRTI). But, injudicious use of antibiotics often leads to antibiotic resistance which is an emerging problem. The objective of this study was taken up to analyse the antimicrobial sensitivity pattern of pathogens isolated from the sputum samples of admitted patients suffering from ALRTI in a tertiary care teaching hospital.

Methods: It is a hospital record-based study with a sample size of 393.

Results: Klebsiella (52.16\%) was the most common organism followed by Acinetobacter (13.49\%) and Pseudomonas (13.23\%) isolated from the sputum sample. Imipenem, piperacillin/tazobactam combination and gentamicin was sensitive against Klebsiella and Pseudomonas and the association were statistically significant. Acinetobacter was resistant to ceftriaxone.

Conclusions: The commonest pathogens isolated from the sputum samples were Klebsiella followed by Acinetobacter and Pseudomonas. Imipenem, piperacillin/tazobactam combination and gentamicin was sensitive against Klebsiella and Pseudomonas.
\end{abstract}

Keywords: Antibiotic resistance, Klebsiella, Acinetobacter, Lower respiratory tract infection

\section{INTRODUCTION}

Acute lower respiratory tract infection (ALRTI) is one of the most common human ailments. The common risk factors causing ALRTI in India includes- overcrowded dwellings, poor nutrition, low birth weight, indoor smoke pollution. ${ }^{1}$

Antibiotics are considered to be the most effective therapeutic agents to combat microbial infections. Due to significant changes in microbial genetic ecology, indiscriminate use of antimicrobials, inappropriate dosing and duration of treatment, over the counter availability of antibiotics to the general public, the spread of antimicrobial resistance is now a global problem. ${ }^{2}$

Antibiotic resistance emerges commonly when patients are treated with empiric antimicrobial drugs. To improve the outcome of serious infections, monitoring of resistance patterns in the hospital is needed. Despite many microbiological laboratories performing routine antibiotic susceptibility testing, the data is neither 
analysed regularly nor disseminated for use by clinicians. ${ }^{3}$ Establishment of surveillance programs to monitor the antimicrobial resistance is the need of the hour. The present study is an attempt to analyse the antimicrobial sensitivity pattern of pathogens isolated from the sputum samples of admitted patients suffering from ALRTI in Tripura Medical College and Dr. B.R. Ambedkar Memorial Teaching Hospital (TMC).

\section{METHODS}

\section{Study design}

This study was a hospital record based retrospective study.

\section{Study setting}

The study was conducted in the Department of Pharmacology and Microbiology, Tripura Medical College and Dr. B.R. Ambedkar Memorial Teaching Hospital.

\section{Study period}

The study duration was one year from October 2015 to September 2016.

\section{Sample size}

393 sputum samples were collected during the study period.

\section{Inclusion criteria}

The sputum samples of clinically diagnosed ALRTI patients admitted in various departments of the hospital during the study period were included.

\section{Exclusion criteria}

Antimicrobial agents that was used infrequently or rarely for sensitivity testing was excluded from the study. The samples with no growth were also excluded.

\section{Study techniques}

The sputum samples were collected from clinically diagnosed ALRTI patients who were admitted in various departments of the hospital during the study period. The samples were processed for culture and sensitivity testing in the department of microbiology. The cultured plates were examined after 24 hours and the reports of culture and sensitivity testing of the samples was collected. The results were interpreted according to the guidelines of the Clinical and Laboratory Standards Institute (CLSI). Antibiotic susceptibility of the isolates was determined by modified Kirby-Bauer disc diffusion method, according to CLSI recommendations. The zones of inhibition were measured and the organisms identified as sensitive or resistant based on standard criteria. ${ }^{4}$ Control strains were used for checking the quality of discs and reagents.

Organisms were identified by their colonial morphology, Gram staining and appropriate biochemical tests using standard techniques. ${ }^{4}$

\section{Ethical approval}

Approval was taken from the Institutional Ethics Committee (IEC).

\section{Statistical analysis}

The results were expressed in percentages and analysed for statistical significance by Chi square test using EPI6 software. $\mathrm{P}$ value $<0.05$ was considered statistically significant.

\section{RESULTS}

During the 12-month study period, a total of 393 sputum samples were analysed. Klebsiella $(52.16 \%)$ was the most frequently isolated bacteria, followed by Acinetobacter (13.49\%) and Pseudomonas (13.23\%).

The common pathogens that were isolated from the sputum sample are shown in Table 1.

Antibiotic sensitivity pattern of Klebsiella is shown in Table 2. Out of 205 sputum samples with Klebsiella, levofloxacin was given in 194 samples. Among those samples, 45 samples were resistant to levofloxacin and 149 samples were found to be sensitive to levofloxacin. Significant association was found between samples of klebsiella sensitivity to levofloxacin. Similarly, amikacin (87.61\%), imipenem (86.24\%), gentamycin (79.86), gatifloxacin (79.75\%), levofloxacin (76.80\%), ciprofloxacin $(76.09 \%)$, piperacillin/tazobactam $(75.84 \%)$ and cefuroxime $(75.58 \%)$ were also found to be sensitive and that was statistically significant.

Antibiotic sensitivity pattern of Acinetobacter is shown Table 3. Out of 49 sputum samples with Acinetobacter 27 were sensitive and 21 was resistant to imipenem. But no statistically significant association was found between them. Likewise, Acinetobacter was sensitive to many other antibiotics like piperacillin/tazobactam, levofloxacin, cefuroxime, amoxiclav etc. but none of them showed significant association. Whereas out of 34 sputum samples, $8(23.53 \%)$ samples were sensitive to ceftriaxone and remaining $26(76.47 \%)$ samples were found to be resistant. This association of ceftriaxone resistance to Acinetobacter was statistically significant.

Antibiotic sensitivity pattern of Pseudomonas is shown in Table 4. Similarly, Pseudomonas was found to be sensitive to imipenem $(83.72 \%)$, piperacillin/tazobactam 
(83.72\%), gentamycin $(84.85 \%)$, ceftazidime/clavulanic acid $(79.41 \%)$, ceftazidime $(67.44 \%)$ and ticarcillin/clavulanic acid (61.54\%). This association was statistically significant.

Table 1: Common pathogens in sputum samples $(n=393)$.

\begin{tabular}{|ll|}
\hline Organisms & N $(\%)$ \\
\hline Klebsiella & $205(52.16)$ \\
\hline Acinetobacter & $53(13.49)$ \\
\hline Pseudomonas & $52(13.23)$ \\
\hline E. Coli & $36(9.16)$ \\
\hline Staphylococcus aureus & $23(5.85)$ \\
\hline Enterobacteriaceae & $09(2.29)$ \\
\hline Citrobacter & $06(1.53)$ \\
\hline MRSA & $05(1.27)$ \\
\hline Edwardsiella & $03(0.76)$ \\
\hline a-haemolytic streptococcus & $01(0.25)$ \\
\hline
\end{tabular}

Table 2: Sensitivity pattern of Klebsiella.

\begin{tabular}{|llll|}
\hline Antimicrobial agents & Total sputum sample & Sensitive $(\%)$ & Resistant $(\%)$ \\
\hline Levofloxacin** & 194 & $149(76.80)$ & $45(23.20)$ \\
\hline Imipenem** & 189 & $163(86.24)$ & $26(13.76)$ \\
\hline Piperacillin/tazobactam** & 178 & $135(75.84)$ & $43(24.16)$ \\
\hline Cefuroxime** & 172 & $130(75.58)$ & $42(24.42)$ \\
\hline Gentamicin** & 144 & $115(79.86)$ & $29(20.14)$ \\
\hline Amoxiclav & 142 & $05(3.52)$ & $137(96.48)$ \\
\hline Amikacin** & 113 & $99(87.61)$ & $14(12.39)$ \\
\hline Cefotaxime & 111 & $56(50.46)$ & $55(49.54)$ \\
\hline Ceftriaxone & 97 & $47(48.45)$ & $50(51.55)$ \\
\hline Ciprofloxacin** & 92 & $70(76.09)$ & $22(23.91)$ \\
\hline Gatifloxacin** & 79 & $63(79.75)$ & $16(20.25)$ \\
\hline Cefepime & 72 & $38(52.78)$ & $34(47.22)$ \\
\hline Cefpodoxime & 43 & $04(9.30)$ & $39(90.70)$ \\
\hline Meropenem & 30 & $29(96.67)$ & $01(3.33)$ \\
\hline Azithromycin & 24 & $11(45.83)$ & $13(54.17)$ \\
\hline Ampicillin & 09 & $0(0.0)$ & $09(100.0)$ \\
\hline Norfloxacin & 05 & $04(80.0)$ & $01(20.0)$ \\
\hline Ceftazidime & 05 & $01(20.0)$ & $04(80.0)$ \\
\hline Ofloxacin & 01 & $01(100.0)$ & $0(0.0)$ \\
\hline
\end{tabular}

${ }^{* *} \mathrm{p}<0.001,{ }^{*} \mathrm{p}<0.05$, S: sensitive; R: resistant.

Table 3: Sensitivity pattern of Acinetobacter.

\begin{tabular}{|llll|}
\hline Antimicrobial agents & Total sputum samples & Sensitive (\%) & Resistant $(\%)$ \\
\hline Imipenem & 49 & $27(55.10)$ & $21(44.90)$ \\
\hline Piperacillin/tazobactam & 48 & $25(52.08)$ & $23(47.92)$ \\
\hline Levofloxacin & 46 & $27(58.70)$ & $19(41.30)$ \\
\hline Cefuroxime & 40 & $02(5.0)$ & $38(95.0)$ \\
\hline Amoxiclav & 38 & $02(5.26)$ & $36(94.74)$ \\
\hline Gentamicin & 35 & $18(51.43)$ & $17(48.57)$ \\
\hline Ceftriaxone* & 34 & $08(23.53)$ & $26(76.47)$ \\
\hline Amikacin & 28 & $13(46.43)$ & $15(53.57)$ \\
\hline Ciprofloxacin & 25 & $12(48.0)$ & $13(52.0)$ \\
\hline Cefotaxime & 17 & $06(35.29)$ & $11(64.71)$ \\
\hline Cefepime & 16 & $04(25.0)$ & $12(75.0)$ \\
\hline Cefpodoxime & 14 & $01(7.14)$ & $13(92.86)$ \\
\hline Ceftazidime & 10 & $05(50.0)$ & $05(50.0)$ \\
\hline
\end{tabular}




\begin{tabular}{|llll|}
\hline Antimicrobial agents & Total sputum samples & Sensitive (\%) & Resistant (\%) \\
\hline Meropenem & 08 & $05(62.50)$ & $03(37.50)$ \\
\hline Norfloxacin & 05 & $02(40.0)$ & $03(60.0)$ \\
\hline Azithromycin & 05 & $01(20.0)$ & $04(80.0)$ \\
\hline
\end{tabular}

**p<0.001, $* \mathrm{p}<0.05$, S: sensitive; R: resistant.

Table 4: Sensitivity pattern of Pseudomonas.

\begin{tabular}{|llll|}
\hline Antimicrobial agents & Total sputum samples & Sensitive $(\%)$ & Resistant $(\%)$ \\
\hline Imipenem** & 43 & $36(83.72)$ & $07(16.28)$ \\
\hline Piperacillin/tazobactam** & 43 & $36(83.72)$ & $07(16.28)$ \\
\hline Ceftazidime* & 43 & $29(67.44)$ & $14(32.56)$ \\
\hline Ticarcillin/clavulanic acid* & 39 & $24(61.54)$ & $15(38.46)$ \\
\hline Levofloxacin & 34 & $31(91.18)$ & $03(8.82)$ \\
\hline Ceftazidime/clavulanic acid* & 34 & $27(79.41)$ & $07(20.59)$ \\
\hline Gentamicin* & 33 & $28(84.85)$ & $05(15.15)$ \\
\hline Amikacin & 28 & $25(89.29)$ & $03(10.71)$ \\
\hline Ciprofloxacin & 21 & $19(90.48)$ & $02(9.52)$ \\
\hline Gatifloxacin & 19 & $17(89.47)$ & $02(10.53)$ \\
\hline Amoxiclav & 08 & $02(25.0)$ & $06(75.0)$ \\
\hline Meropenem & 08 & $08(100.0)$ & $00(0.0)$ \\
\hline Ceftriaxone & 07 & $06(85.71)$ & $01(14.29)$ \\
\hline Cefuroxime & 07 & $01(14.29)$ & $06(85.71)$ \\
\hline Cefepime & 04 & $00(0.0)$ & $04(100.0)$ \\
\hline Azithromycin & 02 & $00(0.0)$ & $02(100.0)$ \\
\hline Cefpodoxime & 01 & $00(0.0)$ & $01(100.0)$ \\
\hline
\end{tabular}

${ }^{* *} \mathrm{p}<0.001,{ }^{*} \mathrm{p}<0.05$, S: sensitive; R: resistant.

\section{DISCUSSION}

The present study showed the types of bacterial pathogens and the antibiotic sensitivity pattern of these pathogens isolated from sputum sample of admitted patients suffering from ALRTI. Klebsiella was the predominant microorganism isolated from these samples $(52.16 \%)$. Klebsiella was also found as predominant organism in studies done by Ahmed et al, Promite et al and Manikandan et al showing 59.7\%, $42.5 \%$ and $28.4 \%$ frequency respectively. ${ }^{5-7}$ In this study, the other common isolated pathogens were Acinetobacter (13.49\%) and Pseudomonas (13.23\%). This finding correlates with the findings of Ali et al. $^{8}$ showing prevalence of Acinetobacter and Pseudomonas to be $13.69 \%$ and $35.35 \%$ respectively. Agarwal et al also found Acinetobacter and Pseudomonas as commonly encountered pathogens and the prevalence was $34.8 \%$ and $23.9 \%$ respectively. ${ }^{9}$

In this study, Klebsiella was sensitive to amikacin, imipenem, gentamycin, gatifloxacin, levofloxacin, ciprofloxacin, piperacillin/tazobactam and cefuroxime and this association was statistically significant. Amikacin and gentamycin were found to be sensitive to Klebsiella in other studies. ${ }^{6,10}$

Acinetobacter was sensitive to many antibiotics e.g., imipenem, piperacillin/tazobactam, cefuroxime etc. but the association was not significant. Rather, ceftriaxone was found to be resistant to $76.47 \%$ samples of Acinetobacter which was statistically significant. Nepal et al in their study also found that Acinetobacter to be resistant to multidrug like amoxicillin, cefixime, ciprofloxacin, azithromycin. ${ }^{11}$ Whereas ceftazidime, cefepime, gentamicin etc. were found to be resistant to Acinetobacter by Thomas et al. ${ }^{12}$

Pseudomonas was highly sensitive $(\mathrm{p}<0.001)$ to imipenem $(83.72 \%)$, piperacillin/tazobactam $(83.72 \%)$, and was sensitive $(\mathrm{p}<0.05)$ to gentamycin $(84.85 \%)$, ceftazidime/clavulanic acid $(79.41 \%)$, ceftazidime $(67.44 \%)$. Gentamycin and amikacin were found to be sensitive to Pseudomonas as shown in the studies done by Mandal et al and Nepal et al whereas Dhakre et al showed ampicillin and piperacillin/tazobactam combination to be highly effective against Pseudomonas..$^{10,11,13}$

\section{CONCLUSION}

The study was conducted to analyse the antimicrobial sensitivity pattern of pathogens isolated from the sputum samples in a tertiary hospital of Tripura. The commonest pathogens isolated from the sputum samples were Klebsiella followed by Acinetobacter and Pseudomonas. Imipenem, piperacillin/tazobactam combination and gentamicin was sensitive against Klebsiella and Pseudomonas and the association was statistically significant. Significant association was also found between Acinetobacter and ceftriaxone resistance. 


\section{ACKNOWLEDGEMENTS}

Authors would like to acknowledge the Principal, Tripura Medical College and Dr. B.R. Ambedkar Memorial Teaching Hospital, Agartala, Tripura for providing the necessary facilities to carry out this study.

Funding: No funding sources

Conflict of interest: None declared

Ethical approval: The study was approved by the Institutional Ethics Committee

\section{REFERENCES}

1. Park K. Acute respiratory infections. 23rd edition. M/s Banaraidas Bhanot; 2015: 169.

2. Goswami NN, Trivedi HR, Goswami AP, Patel TK, Tripathi CB. Antibiotic sensitivity profile of bacterial pathogens in postoperative wound infections at a tertiary care hospital of Gujarat, India. J Pharmacol Pharmacotherapeutics. 2011;2:158-63.

3. National treatment guidelines for antimicrobial use in infectious diseases; 2016.

4. Clinical and Laboratory standards Institute. Performance standard for antimicrobial susceptibility testing, document M100-S16.Wayne. PA: Clinical and Laboratory standards Institute; 2006.

5. Ahmed SMA, Abdelrahman SS, Saad DM, Osman IS, Osman MG, Khalil EA. Etiological Trends and Patterns of Antimicrobial Resistance in Respiratory Infections. Open Microbiol J. 2018;12:34-40.

6. Promite S, Ahsan S, Akhter MZ, Saha SK. Characterization and Antibiotic Sensitivity Profile of Bacteria Isolated from Patients with Respiratory Tract Infections in Bangladesh. Dhaka Univ J Pharm Sci. 2017;16:235-44.

7. Manikandan C, Amsath A. Antibiotic susceptibility of bacterial strains isolated from patients with respiratory tract infections. Int $\mathbf{J}$ Pure Appl Zool. 2013;1:61-9.

8. Ali I, Butt MA. Antibiotic Susceptibility Pattern of Bacterial Isolates from Patients of Respiratory Tract Infection at 43 Centers in Punjab, Pakistan. Clin Exp Pharmacol. 2017;7:1-7.

9. Agarwal R, Gupta D, Ray P, Agarwal AN, Jindal SK. Epidemiology, risk factors and outcome of nosocomial infection in a respiratory intensive care unit in North India. J Infec. 2006;53:98-105.

10. Mandal AK, Saha P, Mondal T, KundU PK. Antibiotic susceptibility pattern of bacterial strains isolated from children with upper respiratory tract infection. J Dent Med Sci. 2018;17:1-6.

11. Nepal R, Singh A, Shrestha B, Shrestha S, Joshi DM, Joshi RD. Antibiotic susceptibility pattern of gramnegative isolates of lower respiratory tract infection. J Nepal Health Res Counc. 2018;16:22-6.

12. Thomas B, Sukumaran P, Oommen S, Midhun M, George D. Antimicrobial resistance of Acinetobacter baumannii infection of lower respiratory tract and mortality- A cross sectional study from a tertiary care teaching hospital in Kerala. Indian $\mathbf{J}$ Immunol Respiratory Med. 2018;3:183-7.

13. Dhakre S, Reddy P, Kulmi M, Goyal C. Antibiotic susceptibility pattern of bacterial isolated from patients of respiratory tract infection in a tertiary care hospital of Central India. Int J Basic Clin Pharmacol. 2017;6:1740-6.

Cite this article as: Debnath $S$, Bhaumik D,

Chakraborty M, Ghosh R, Das L, Bhattacharjee P. Antibiotic sensitivity pattern of bacterial isolates from sputum samples of admitted patients with acute lower respiratory tract infections in a tertiary care teaching hospital of Tripura: a hospital record-based study. Int J Basic Clin Pharmacol 2020;9:254-8. 